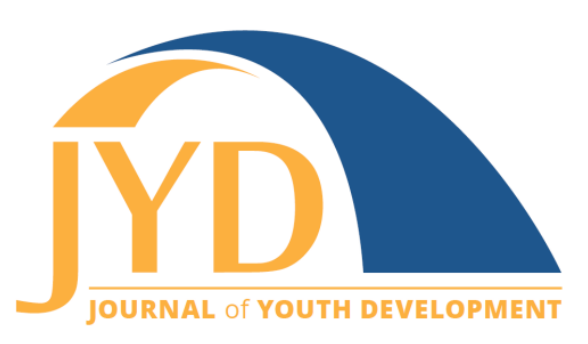

http://jyd.pitt.edu/ | Vol. 15 Issue 1 DOI 10.5195/jyd.2020.795 | ISSN 2325-4017 (online)

\title{
Camp Organizational Support for Creativity Among New and Returning Camp Counselors
}

\author{
Myles L. Lynch \\ University of New Hampshire \\ mlynch299@gmail.com \\ Cindy L. Hartman \\ University of New Hampshire \\ cindy.hartman@unh.edu \\ Nate E. Trauntvein \\ Utah State University \\ nate.trauntvein@usu.edu \\ Cari A. E. Moorhead \\ University of New Hampshire \\ cari.moorhead@unh.edu
}

\begin{abstract}
Creativity supports interest, imagination, empowerment, intrinsic motivation, and overall engagement. Satisfied employees, who are supported in their creativity, have increased performance, motivation, and commitment. Residential summer camp is a demanding 24-hour job in which camp counselors use creativity on a regular basis via lesson planning, teaching activities, resolving conflict, and living within close proximity to coworkers. The purpose of the current study was to explore organizational support for creativity among first-year and returning staff at the beginning and end of one season of employment. Camp counselors ( $\mathrm{n}=113$ ) participated in the current study utilizing quantitative and qualitative methods. Quantitative analysis compared pretest data on creativity to posttest items using paired samples t-tests. First-year and returning counselors indicated significant decreases in perceptions of the camp organization valuing creativity. Counselors'self-identification as a creative employee significantly decreased among returning employees. Qualitative data analysis produced 46 independent responses and 3 content areas describing barriers to creativity, including personal (intimidation, inexperience), structural (time/money), and camp traditions (status quo) barriers. Summer camps should prioritize support for creativity as a vital component needed for a positive work culture. Ultimately, a camp mission, culture,
\end{abstract}

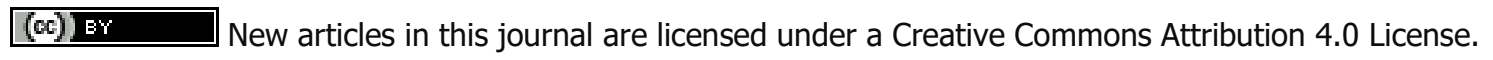
This journal is published by the University Library System, University of Pittsburgh and is cosponsored by the University of Pittsburgh Press. The Journal of Youth Development is the official peer-reviewed publication of the National Association of Extension 4-H Youth Development Professionals and the National AfterSchool Association. 
Journal of Youth Development | http://jyd.pitt.edu/ | Vol. 15 Issue 1 DOI 10.5195/jyd.2020.795

\section{Camp Support for Counselor Creativity}

and training, which support creativity may empower counselors (of various experience levels) to create new ideas, camp traditions, and activities.

Key words: camp counselor, creativity, multi-method, organizational behavior, professional development

\section{Introduction}

In the United States, summer camp is an 18-billion-dollar industry that hires around 1.5 million staff every year (American Camp Association, 2015). Camp counselors are typically within the developmental stage of emerging adulthood (18 to 25 years old) in which identity formation, exploration of possibilities, and instability are key factors (Arnett, 2000). While some scholars assert emerging adulthood is still not clearly defined, or a formalized state of development (Hendry \& Kloep, 2007), it provides an explanation for understanding camp counselor needs and perceptions of a summer camp work context (Hendry \& Kloep, 2007).

Prior research asserts that well-organized summer camps provide camp counselors with a supportive work environment that includes opportunities for professional development, lifelong friendship, sense of community, identity exploration, and college and workplace readiness (DeGraaf \& Glover, 2003; Duerden et al., 2014; McCole, Jacobs, Lindley, \& McAvoy, 2012; Whittington \& Garst, 2018; Wilson \& Sibthorp, 2018). The benefits of summer camp may lend professional support to camp counselors who are oftentimes just starting out in the workforce.

Creativity has been extensively researched in school and work contexts; however, no known studies empirically address workplace creativity among new and returning camp counselors in a residential summer camp (Amabile, Conti, Coon, Lazenby, \& Herron, 1996; Goor \& Rapoport, 1977; Lynch, Hegarty, Trauntvein, \& Plucker, 2018). Understanding and implementing creativity for counselors in a camp context may help support novel training techniques and professional development opportunities throughout the summer. This study explored differences in creativity among first-year and returning staff at the beginning and end of a single camp summer season.

\section{Theoretical Foundation}

Creativity is "the interaction among aptitude, process, and environment by which an individual or group produces a perceptible product that is both novel and useful as defined within a social context" (Plucker, Beghetto, and Dow, 2004, p. 90). For something to be considered creative, it needs to be both new (novel) and have appropriate use (utility) within a social context. In 


\section{Camp Support for Counselor Creativity}

summer camp, creativity may be enacted through theming activities, creating new traditions, or offering training focused on creativity (Ellis, Jiang, Lacanienta, \& Carroll, 2019; Hosseini \& Watt, 2010; Lynch et al., 2018). Prior studies assert that effective implementation (or 'buy-in') of camp themes involves co-creation of activities which is based on awareness of camper needs, counselor experience, and overall expectations of the camp traditions and values (Lacanienta, Ellis, Taggart, Wilder, \& Carroll, 2018). In other words, instilling creativity and components of theming in camp takes more than doing something new, but must also include an awareness of lived experience, activity structure, and camp tradition (Ellis et al., 2019).

Within the United States, creativity has been on the decline since the 1990's, based on the Torrance Test for Creative Thinking assessments (Kim, 2011). This decline could be attributed to numerous factors including the amount of time spent in front of screens, dwindling recess and imaginative free play in school, or low self-efficacy and confidence regarding creative identity and ability (Kim, 2011; Runco, 2015; Russ, 2014; Russ, Robins, \& Christiano, 1999; Tierney \& Farmer, 2011). The decline could also be attributed to nature deficit disorder, in which psychological and behavioral ailments emerge because of children spending less time outside (Louv, 2008). The decline in creativity is troubling because innovation and critical thinking are essential skills for future employee and organizational success (Plucker, Kaufman, \& Beghetto, 2015). This is because the production of novel and applicable ideas and practices has become paramount in modern organizations. Prior research has focused solely on the role camp plays for supporting camper creativity in a residential camp setting (Lynch et al., 2018). However, the current study unpacks the role camp plays in supporting creativity in staff.

Summer camp provides a challenging outdoor work setting for camp counselors to explore different possibilities and methods of instruction. In one study, immersion in natural settings was shown to enhance creativity after an Outward Bound experience in which technology was not readily available (Atchley, Strayer, \& Atchley, 2012). Furthermore, at-work creativity is enhanced when people feel a sense of volition and freedom in their tasks instead of being controlled by supervisors, rigid structures, or coworker judgement (Van den Broeck, Vansteenkiste, Witte, Soenens, \& Lens, 2010; Gagné \& Deci, 2005). For instance, employees feeling they have a voice and an opportunity to make structural changes is linked to creative performance, job satisfaction, and empowerment (Oldham \& Cummings, 1996; Zhou \& George, 2001). Prior research asserts that employee creative role identity, organizational value of creativity, and expectations for creativity are all significant predictors for support of creativity in various work contexts (Tierney \& Farmer, 2002, 2011). For the current study, the prior 


\section{Camp Support for Counselor Creativity}

constructs were used as measures to explore differences in creativity among camp counselors in a residential camp setting.

\section{Role Identity Creative Employee (RICE)}

An individual's behavior is largely informed based on self-views (identity) and the structure of their respective social context. Self-efficacy-or the belief an individual has in their ability to execute a certain behavior-influences motivation and the desire and confidence to engage in specific behaviors, one of which is creativity (Bandura, 1997; Huang, Krasikova, \& Liu, 2016). The construct of creative self-efficacy may influence the identity and motivation of an employee's role within an organization in relation to how they view their own creativity. In other words, an employee's creative role identity is largely based on prior work experience, selfefficacy beliefs, and confidence to implement new ideas in the workplace (Tierney \& Farmer, 2002 , 2011). Therefore, role identity as a creative employee is based on the individual employee's self-perception (as being a creative person) and whether they feel a work setting creates mechanisms to support and implement new ideas.

A summer camp culture includes traditions, policies, physical space, procedures, and social practices which can either support or undermine new ideas. Camp directors, who consider the importance of creativity, must account for prior counselor experiences related to creativity when introducing new training and ideas for activities (i.e., theme days, novel activities, and traditions, etc.). Self-efficacy helps to explain the culture of camp as being co-constructed based on job experience, personal beliefs, and a dynamic social interplay between first-year and returning staff expectations of creativity (Bandura, 1997; Tierney \& Farmer, 2002, 2011).

Creativity is often mischaracterized as being a special skill held by a few "lone geniuses" instead of a universal skill in which social context and positive affect are necessary components (Amabile, Barsade, Mueller, \& Staw, 2005; Montuori \& Purser, 1995). However, prior research suggests that whether creativity is domain general or domain specific, it can be enhanced using appropriate context and facilitation (Plucker et al., 2004). Therefore, employee creativity may be supported (or hindered) based largely on workplace expectations (from management and coworkers) and understanding of creative self-efficacy at an individual level. In other words, how employees self-identify as being creative (or not) is influenced by experience (i.e., new and returning) and current organizational support (Farmer, Tierney, \& Kung-Mcintyre, 2003; Grube \& Piliavin, 2000). 


\section{Camp Support for Counselor Creativity}

\section{Perception of Organizational Value of Creativity (POVC)}

Companies that allow for a degree of flexibility and allowance of task negotiation, rather than rigid and structured tasks, tend to have more intrinsically motivated, creative, and satisfied workers (Amabile, 1997; Van den Broeck et. al., 2010). Staff training, managerial expectations, and workplace culture all play an important role in employee perceptions and motivation (intrinsic and extrinsic) for valuing and implementing creativity in the workplace (Yoon, Sung, Choi, Lee, \& Kim, 2015). Employees must feel confident that their new ideas will be considered (and potentially accepted) by managers in order to build their creative self-efficacy.

In residential summer camp, one way to understand the value of creativity is via the social process of reflexivity. Reflexivity, a mediating mechanism for social interaction, asserts that social contexts act within a continuous loop in which actions are largely based on social cues, past experiences, and traditions which emerge in their environment and serve as a regulatory process for group cohesion (Shin, Kim, \& Lee, 2017; Soros, 2013). For example, reflexivity may help to explain how camp counselors adjust and adhere their actions (or inactions) according to social cues and expectations from the environment, larger camp community, and traditions of the social context (Archer, 2010; Soros, 2013). If camp counselors are expected to act creatively (by management, coworkers, or social norms) they will likely adjust to fit that norm. However, if counselors are not expected to be creative, implement new activities, or value creativity, they may not consider creativity as an important component of their job. Using reflexivity, creativity becomes largely a constructed (rather than discovered or subjective) social act, which is either supported or inhibited based on various factors including culture, expectations, attitudes, and symbols (Glăveanu, 2015). In this sense, the way(s) an organization values creativity is paramount for creating a camp culture that considers novel ideas and supports counselor ideas.

\section{Perceived Coworker Expectations for Creativity (PCEC)}

Unlike most traditional work settings, in which employees return home after work, residential camp counselors live, eat, and work together 24 hours a day. Therefore, job role expectations are largely formed through the culture and interactions among employees who are placed in an immersive social setting. Expectations regarding how to behave in various social settings are a major source of an individual's self-concept and their motivation to complete a task (Tierney \& Farmer, 2011). Furthermore, coworkers can be a major source for encouraging or diminishing creativity through communication, feedback, and social cues (Woodman, Sawyer, \& Griffin, 


\section{Camp Support for Counselor Creativity}

1993). Therefore, camp counselor expectations in relation to creativity may be influenced based on coworker expectations. How employees are expected to act is an important component to consider if camp directors wish to create an autonomy-supportive work setting.

\section{Autonomy-Supportive Camp and Creativity}

Creativity is an organizational expectation and contributes to overall work climate, job satisfaction, and the production of new ideas (Amabile et. al., 1996; Ko \& Butler, 2007; Zhou \& George, 2001). Furthermore, creativity is important because it is an essential tool for critical thinking, innovation, openness to experience, and risk-taking (Amabile, 1997; McCrae, 1987). Workplaces are social settings, and consist of values, belief systems, attitudes, and managerial expectations for how employees should appropriately function within their respective context (Bolman \& Deal, 1991; Smith, Organ, \& Near, 1983). In this regard, competent and effective employees act as members of a work community in which trust, communication, creativity, and engagement contribute to the overall work climate (Ekvall, 1996). Within work contexts, job expectations can often vary between new and more experienced employees. More experienced employees have a sense for how things already operate, whereas new employees are still trying to adjust to the job role expectations (Bolman \& Deal, 1991).

High-performing companies understand and respond to the needs of employees of varying experience (camp counselors) as well as different customer needs (campers, camp parents), and appropriately challenge workers to do a superior job (Bolman \& Deal, 1991). Furthermore, prior research related to Self-Determination, links the fulfillment (or lack thereof) of the needs of autonomy, competence, and relatedness with creativity of employees (Eisenberger \& Shanock, 2003; Oldham \& Cummings, 1996; Ryan \& Deci, 2000). Creativity is enacted when managers intentionally support self-efficacy beliefs regarding creativity and therefore better support staff who internalize the goals and mission of an organization (Gagné \& Deci, 2005; Tierney \& Farmer, 2002, 2011). In other words, workplaces that are supportive of creativity allow employees to make choices (autonomy), managers provide a meaningful rationale for tasks, and systems are in place that build self-efficacy, confidence, and community (Gagné, \& Deci, 2005; Bolman \& Deal, 1991; Tierney \& Farmer, 2002).

Optimal functioning among employees is best enacted when creativity, flexibility, a sense of purpose, coworker relatedness, and positive supervisor relations are considered important for task performance and behavior (Eccles \& Wigfield, 2002; Kasser, Davey, \& Ryan, 1992; Shalley, Zhou, \& Oldham, 2004). Positive and supportive contexts enhance creativity and the production 


\section{Camp Support for Counselor Creativity}

of new ideas (Amabile et al., 2005). If camps wish to maintain a creative environment, increasing the level of support for autonomy and choice for counselors may be critical for producing new ideas and staying relevant (Amabile et al., 2005; Hill \& Sibthorp, 2006).

Features to consider in an autonomy-supportive summer camp include instructional style used by leaders, which can be either camper- or leader-centered; characteristics of program areas, which may include differences in type of activity such as sports, games, athletics, and the arts; gender differences; and overall cultural attitudes of the specific camp (competitive or noncompetitive) (Henderson 2007; Hill \& Sibthorp, 2006; Ramsing \& Sibthorp, 2008; Sheldon, Williams, \& Joiner, 2003). Oftentimes, camps may become "stuck" in adhering to rigid traditions and the status quo, which may hinder creativity and idea generation. Ultimately, camps that are more flexible in their approach to training (i.e., counselor choice and activity offerings) may be more effective in supporting and delivering creative programming.

\section{The Present Study}

The purpose of the current study was to explore differences in workplace creativity among firstyear and returning camp counselors from the beginning to the end of one season of camp employment. We considered the following research questions:

1. What are the differences in organizational value of creativity, role identity of creativity, and coworker expectation of creativity among first-year and returning staff from beginning to end of employment?

2. What are the differences in organizational value of creativity, role identity of creativity, and coworker expectation of creativity between first-year and returning camp counselors at the beginning and end of employment?

3. What are barriers to workplace creativity among camp counselors?

\section{Methodology}

\section{Research Procedures}

Data were collected at one traditional rural coed residential summer camp in the northeastern United States. All participants completed a paper and pencil survey in the camp dining hall two times throughout the summer. Each survey took around 20 minutes to complete and the first author administered both surveys in person. The first iteration occurred on the final day of staff training, as this is characteristically when counselors know what to expect from the job. The 


\section{Camp Support for Counselor Creativity}

second iteration was conducted on the last day of camp, after campers had left. To remain consistent, the same instructions and survey items were used for both the pre- and post-camp test. All participants were aged 18 years or older and informed consent was successfully received from every participant prior to commencement of data collection. All participants were paid employees at the camp. Additionally, the first author's institutional review board approved this research study prior to data collection.

\section{Quantitative Analysis}

A multi-method design, using quantitative and qualitative data and analysis approaches, was used for the current study. All quantitative data were analyzed using IBM SPSS Statistics (Version 25.0). Baseline (i.e., pretest) items pertaining to creativity were compared to posttest items using paired samples t-tests. Three quantitative instruments were adopted based on prior organizational behavior and job satisfaction studies related to creativity (Tierney \& Farmer, 2011, 2002). The instruments included role identity as a creative employee scale ([RICE]; (Callero, 1985; Callero, Howard, \& Piliavin, 1987); the sufficiency of originality subscale of the Kirton Adaption-Innovation Inventory, which measured perceived coworker expectations for creativity ([PCEC]; Kirton, 1976); and the perception of organizational value of creativity scale ([POVC]; Amabile et al., 1996). The scales were modified slightly by the researchers based on the features of summer camp. For example, the word "work" was replaced with the word "camp" on all items. Furthermore, the word "employee" was replaced with "camp counselor."

A reliability analysis was performed for the modified creativity instruments to test for internal consistency. A Cronbach's alpha score was recorded for each sub-domain as well as the recalculated alpha scores if each sub-item was removed. Each sub-domain for creativity received acceptable Cronbach's alpha scores, with the lowest being PCEC $(a \leq .66)$, still considered to be an acceptable value in survey statistics. The next lowest sub-domain was RICE $(a \leq .70)$, which is considered a moderate value. The remaining sub-domain of POVC had a high Cronbach Alpha score $(a \leq .83)$.

\section{Qualitative Analysis}

Qualitative data originated from one open-ended question at the end of the survey: "Is there anything that keeps you from being as creative as you would like at Camp [Name of camp]? Please explain." The qualitative responses $(n=46)$ explaining the barriers to creativity were independently analyzed by two researchers using an inductive, constant comparison method 


\section{Camp Support for Counselor Creativity}

(Corbin \& Strauss, 2015). Data were compared for similarities and differences to develop initial coding concepts, and then grouped into categories of broad categories of factors affecting perceptions of barriers to creativity (Corbin \& Strauss, 2015). To establish trustworthiness, the two researchers met after their independent analyses to confer over initial codes, discussing discrepancies at length with respect to previous knowledge and research conducted on emerging adulthood and camp settings. Each code was then placed into relevant overarching categories (Nowell, Norris, White, \& Moules, 2017). While the quantitative and qualitative data were analyzed separately and the results are presented separately, the discussion provides an interpretation and implications based on both forms of data collectively.

\section{Results}

\section{Quantitative Results}

A total of 113 seasonal camp counselors participated in both the pretest (last day of staff training) and posttest (end of employment); one participant did not complete the posttest and was not included in the analysis. All participants attended a mandatory 7-day training orientation prior to the beginning of camp, followed by working at a summer camp for a varied amount of time. The 7-day training focused on duties, responsibilities, and training for camp counselors; it did not focus on creativity. Participant characteristics are summarized in Table 1. 
Table 1 Characteristics of Study Participants $(n=113)$

\begin{tabular}{|c|c|c|}
\hline Age in years $M=20.5, S D=2.07$ & $n$ & $\%$ \\
\hline $19-20$ & 45 & $39.8 \%$ \\
\hline $21-22$ & 35 & $30.9 \%$ \\
\hline $23-24$ & 25 & $22.1 \%$ \\
\hline $25-28$ & 7 & $6.1 \%)$ \\
\hline \multicolumn{3}{|l|}{ Years as staff $M=2.46, S D=1.62$} \\
\hline $1^{\text {st }}$ year & 44 & $38.9 \%$ \\
\hline Returning & 69 & $61.1 \%$ \\
\hline \multicolumn{3}{|l|}{ Years as camper $M=2.46, S D=1.62$} \\
\hline 0 & 32 & $28.3 \%$ \\
\hline $1-5$ & 13 & $11.5 \%$ \\
\hline $6-8$ & 42 & $37.1 \%$ \\
\hline $9-11$ & 26 & $23.0 \%$ \\
\hline \multicolumn{3}{|l|}{ Gender } \\
\hline Female & 70 & $61.9 \%$ \\
\hline Male & 41 & $36.2 \%$ \\
\hline Other & 2 & $1.7 \%$ \\
\hline \multicolumn{3}{|l|}{ Schooling a } \\
\hline High school & 2 & $1.8 \%$ \\
\hline College & 80 & $70.2 \%$ \\
\hline Other ${ }^{b}$ & 29 & $25.4 \%$ \\
\hline
\end{tabular}

a Two counselors did not report their level of education. ${ }^{b}$ Includes college graduate, gap year, did not attend college.

Paired $t$-tests were used to assess the difference in workplace creativity among first-year and returning staff from beginning to end of employment (research question 1). Based on experience (first year/returning), statistically significant decreases from pre- to post-camp assessment were found in POVC among both first-year $(p<.001, t=4.50)$ and returning staff ( $p<.001, t=3.79$ ) cohorts (Table 2 ). RICE was relatively stable among first-year staff $(\mathrm{p}=.807, \mathrm{t}=.245)$. However, RICE significantly decreased among returning staff members ( $p<$ $.05, t=2.27$ ) (Table 2). PCEC stayed roughly the same and had no significant changes from pre- to post-camp. 
Table 2: Changes in Creativity Expectations Across Camp Season by Counselor Type

\begin{tabular}{|l|c|c|c|c|}
\hline First-year counselors $(\boldsymbol{n}=\mathbf{4 4})$ & Pre $(\boldsymbol{S D})$ & Post $(\boldsymbol{S D})$ & $\boldsymbol{t}$ & $\boldsymbol{p}$ \\
\hline POVC & $5.33(.755)$ & $4.94(.843)$ & 4.50 & $<.001^{* * *}$ \\
\hline RICE & $4.31(1.17)$ & $4.28(.876)$ & .246 & .807 \\
\hline PCEC & $3.95(.759)$ & $4.07(.607)$ & -1.243 & .221 \\
\hline Return counselors $(\boldsymbol{n}=\mathbf{6 9})$ & & & & \\
\hline POVC & $5.36(.556)$ & $5.05(.737)$ & 3.79 & $<.001^{* * *}$ \\
\hline RICE & $4.53(.895)$ & $4.29(1.16)$ & 2.27 & $.026 *$ \\
\hline PCEC & $4.31(.671)$ & $4.28(.870)$ & .354 & .724 \\
\hline
\end{tabular}

Note. POVC $=$ Perception of organization value of creativity. RICE $=$ Role identity as a creative employee. PCEC $=$ Perceived coworker expectations for creativity .

$* p<.05, * * p<.01, * * * p<.001$

To assess the difference between first-year and returning staff members' creativity expectations two one-way ANOVAs were performed-one for the pretest (Table 3) and again for the posttest (Table 4) with experience level (first-year and returning) as the grouping factor. Pretest results indicated statistically significant differences between first-year and returning staff in PCEC $(p<$ .05). In other words, at the beginning of camp, returning staff members had significantly higher expectations for creativity than new staff members. Posttest results showed no statistically significant differences between first-year and returning staff members pertaining to creativity (Table 4).

Table 3: Pre-Camp Differences Between First-Year $(n=44)$ and Returning Counselors' $(n=69)$ Creativity Expectations

\begin{tabular}{|l|c|c|c|c|}
\hline & First year (SD) & Return (SD) & $\boldsymbol{F}$ & Sig \\
\hline POVC & $5.33(.764)$ & $5.36(.556)$ & .046 & .831 \\
\hline RICE & $4.29(1.18)$ & $4.53(.895)$ & 1.40 & .239 \\
\hline PCEC & $3.95(.766)$ & $4.31(.671)$ & 7.06 & $.009 *$ \\
\hline
\end{tabular}

Note. POVC $=$ Perception of organization value of creativity. RICE $=$ Role identity as a creative employee.

PCEC $=$ Perceived coworker expectations for creativity .

$* p<.05, * * p<.01, * * * p<.001$ 
Camp Support for Counselor Creativity

Table 4: Post-Camp Differences Between First-Year $(n=44)$ and Returning Counselors' $(n=69)$ Creativity Expectations

\begin{tabular}{|l|c|c|c|c|}
\hline & First year (SD) & Return (SD) & $\boldsymbol{F}$ & Sig \\
\hline POVC & $4.93(.852)$ & $5.05(.737)$ & .589 & .444 \\
\hline RICE & $4.27(.884)$ & $4.29(1.16)$ & .011 & .915 \\
\hline PCEC & $4.06(.608)$ & $4.28(.870)$ & 2.23 & .138 \\
\hline
\end{tabular}

Note. POVC $=$ Perception of organization value of creativity. RICE $=$ Role identity as a creative employee.

PCEC $=$ Perceived coworker expectations for creativity.

\section{Qualitative Results}

The quantitative analyses demonstrated differences between first-year and returning camp counselors' expectations for creativity at the beginning of camp. However, at the end of camp there were no substantive quantitative differences between new and returning counselors. Due to the lack of significant results on post-camp creativity scores, the qualitative data from new and returning counselors were aggregated to understand categories related to barriers to creativity among all counselors. In the qualitative analyses, we analyzed responses $(n=46)$ pertaining to barriers to creativity. Counselor comments were coded into the three categories of barriers: inter/intra personal barriers (20.5\%), structural barriers (11.5\%), and camp traditions barriers (8.5\%) (Table 5). Subcategories are provided to further describe overarching categories of barriers. Responses indicating no barriers and/or expressions of positive views of support for creativity at camp (11.2\%) were also consolidated and categorized to show a diversity of responses and perceptions that the camp environment supports. There were no systematic differences found among respondents and non-respondents to the open-ended question. Barriers associated with creativity and their interpretation are discussed in further detail in the ensuing sections. 


\section{Camp Support for Counselor Creativity}

Table 5: Frequency of categories of barriers and creativity $(n=46)$

\begin{tabular}{|c|c|c|}
\hline Theme & N & Valid \% \\
\hline Inter/intrapersonal barriers & 24 & 20.5 \\
\hline Intimidation & 14 & 12.0 \\
\hline Inexperience & 10 & 8.5 \\
\hline Structural barriers & 13 & 11.5 \\
\hline Safety/Guidelines & 6 & 5.0 \\
\hline Time/Money & 7 & 6.0 \\
\hline Camp traditions barriers & 9 & 8.0 \\
\hline No barriers & 10 & 11.2 \\
\hline
\end{tabular}

Note: Pre- and post-camp frequencies were combined. Percentages may not equal 100 because of rounding

\section{Inter/Intrapersonal Barriers}

The category inter/intrapersonal barriers to creativity received the most comments among camp counselors $(n=24)$. The inter/intrapersonal barriers contained the sub-themes of intimidation ( $n=14)$ and inexperience $(n=10)$. Respondents frequently suggested that the numerous inter/intrapersonal barriers to creativity involved "stigma" in their work environment related to feeling intimidated and inexperienced when introducing new or creative ideas. For example, one respondent stated: "Slight judgement [from coworkers], slight lack of support, apprehension due to fear of failure." Several respondents suggested that "judgement," "inexperience," and "strong views" associated with new and creative ideas were substantial barriers to having a "voice" related to creativity. For example, one respondent explained, "There are many strong personalities at camp and [it's] sometimes difficult to not have your own ideas overshadowed by theirs." Counselors also noted impacts associated with inexperience and personal skill stemming from "fear" and "personal ability" related to creativity. One respondent observed, "Fear of failure [related to creativity]" and "The only thing that keeps me from being creative is my own personal ability."

\section{Structural Barriers}

The category of structural barriers to creativity received a moderate number of responses among counselors $(n=13)$. Structural barriers included two sub-themes pertaining to safety and guidelines $(n=6)$ and time and money $(n=7)$. Safety and guideline barrier sentiment 


\section{Camp Support for Counselor Creativity}

were highlighted as creativity being inhibited in camp due to "[policies and procedures] of excessive camper safety," "strictness," and "sticking to a schedule." Another counselor wrote, "Often as [camp] counselors, even in our free time, we cannot go down to certain activity areas due to supervision." Counselors also indicated barriers to creativity associated with time and money in the form of "not enough planning time" and "availability of material." One counselor wrote, "Camp restrictions include budget and time constraints as well as a need to offer diverse programming. For example: Not everyone can teach canoeing." A counselor's desire to teach a variety of activities, instead of only "canoeing" relates to organizational structure and how programmatic logistics and scheduling may influence perceptions of creativity. Another counselor wrote, "There are so many things to plan during staff orientation that I don't put as much creative thought into something as I would like."

\section{Camp Traditions Barriers}

The category of camp traditions barriers received the fewest responses associated with barriers among camp counselors $(n=9)$. Camp traditions barriers related to overall personal beliefs surrounding how camp oftentimes gets stuck in monotonous activities and procedures that inhibit creativity. For instance, counselors noted barriers to creativity related to adhering to the "status quo" or "doing things because they have always been done that way." For example, one participant explained, "Often, people here prefer that we do things the way they've always been done. If we want to do things our own way, it's not always encouraged." Another counselor noted, "Staff members being too comfortable with the way things are, even though they can be improved upon." One other participant noted the managerial impacts on creativity, "Upper leaders being intimidating, and traditions can often hide creativity." One counselor noted barriers based on traditional values and expectations: "I want to teach singing and acting but boys don't want to take those activities, so they don't run." Camp traditions barriers may relate to camps catering their programming only to activities which "sell" rather than providing counselors with options to create new activities.

\section{No Barriers}

Qualitative results indicated distinct groups related to interpersonal, intrapersonal, structural, and camp traditions barriers to creativity within the camp work context. Some counselors also provided positive comments $(n=10)$ worth noting, which included sentiment that camp allows for "expression," "opportunities," and is very "helpful" in relation to creativity. One counselor wrote, "Here at camp, creativity is the name of the game. Sometimes, the more wild and crazy 


\section{Camp Support for Counselor Creativity}

the idea, the better it will run." Another counselor felt strong support for creativity and wrote, "I feel like my most creative self here at camp." Although the majority of comments $(n=46)$ related to barriers to creativity at camp, positive comments $(n=10)$ indicated that creativity is supported and provides a positive impact for summer camp.

\section{Discussion}

Creativity is a vital skill for a positive and productive workplace (Plucker et al., 2015). How people view their own confidence in creativity is due in part to self-efficacy beliefs, expectations, and prior experience (Bandura, 1977). The current study found significant decreases among both first-year and returning counselors related to perceptions of organizational valuing of creativity from the start to end of seasonal employment. This decrease may be due in part to counselors having less organizational support or resources for creativity throughout the summer. Overall decreases in organizational valuing of creativity could also relate to staff burnout and exhaustion throughout the summer, with counselors (and administration) maintaining the status quo or underperforming instead of producing new and fresh ideas (Bailey, Kang, \& Kuiper, 2012; Wahl-Alexander, Richards, \& Washburn, 2017). Counselors may be continuously teaching the same activity and therefore not have opportunities to develop different skill sets. The attrition of perceived organizational support for creativity is not unique to summer camp settings.

In order to promote creativity and innovation, organizations of all types must continually encourage a creative mindset. Encouragement can come in the form freedom and autonomy to make mistakes and experiment, which in turn creates a sense of community among employees (McCole, Jacobs, Lindley, \& McAvoy, 2012). Opportunities for staff to try new things creates a supportive work culture which may ultimately enhance workplace creativity and imagination.

Another notable finding was the significant pretest differences from first-year and returning counselors related to coworkers' expectations for creativity. Interestingly, the pretest differences related to expectations for creativity among first-year and returning staff diminished on the posttest, which indicated first-year staff had "caught up" and were expected to be as creative as returning staff members by the end of the summer. This difference may be due to higher expectations at the beginning of the summer for creativity among returning staff as opposed to new staff who are not yet familiar with the culture or expectations in camp. Returning staff may want to emulate and set an example from prior summers and continue 


\section{Camp Support for Counselor Creativity}

traditions and expectations related to creativity. The process of social continuation of creative expectations may be explained using the concept of reflexivity, in which social processes and personal actions are due in part to the environment as well as the individual (Soros, 2013).

Although the perceived differences of organizational and coworker creativity among first-year and returning camp counselors were notable, the deeper discussion revolved around the nuanced interpretation of the perceived barriers to creativity. Counselors identified barriers to creativity in their residential summer camp work context due to various interpersonal, intrapersonal, structural, and camp traditions factors. Camp counselors identified barriers to creativity that were personal and individualized as well as associated with larger traditions and camp culture. Responses from the open-ended comments indicated creativity may be inhibited at an individual level due to creative self-efficacy and personal confidence as well as a structural and larger camp culture level due in part to expectations, rules, guidelines, time, traditions, and intimidation.

To maximize ideas and positive culture, it is important to understand camp counselors' expectations and perceptions of creativity. Returning and new counselors' views should be considered when incorporating new ideas and expectations related to creativity. Camp counselors have a reputation for being creative and fun; however, this stereotype falls into the myth of creativity as being individualized, instead of as a largely social and communal process (Plucker, et al., 2004). Creativity myths should be addressed by camp directors in hopes of shifting the narrative of camp counselor expectations and getting input from less vocal or new counselors. Ultimately, to support creativity, summer camps should strive to achieve what researchers have described as an autonomy-supportive setting, in which work conditions are present that support choice, freedom (within limits), and competence among counselors (Deci \& Ryan, 2012; Ryan \& Deci, 2002).

The results of this study indicate that more experienced staff had significantly higher expectations for creativity at the beginning of the summer. The data suggest that the new staff caught up to their more seasoned peers in their expectation for creativity, perhaps due in part to their familiarity with the work involved with being a camp counselor. Although increased expectation of creativity among new staff is beneficial, managers need to consider how to better support returning staff in their expectations for creativity. Differences in expectations for creativity among counselors may relate to the description of organizational work climate for creativity or intentionality of programmatic features (Ekvall, 1996; Garst, \& Gagnon, 2016). In 


\section{Camp Support for Counselor Creativity}

addition, supporting creativity is linked to empowerment and motivation at work, which may help support timid or less experienced counselors (Zhang \& Bartol, 2010).

Oftentimes, summer camps focus training on technical skills such as lifeguard training, emergency procedures, or behavioral management strategies. Camp directors should consider creativity as an additional skill to incorporate using in-service training throughout the summer. Although technical skills are important, camps should use training time to focus on less tangible skill development, such as creativity. In-service creativity workshops could focus on idea generation, activity theming, and ways to support choice and autonomy for counselors (Ellis, Jiang, Lacanienta, \& Carroll, 2019). Ultimately, value for creativity throughout the summer may help camp counselors in their autonomy support, which in turn may support staff through choice of tasks and implementation of new ideas

\section{Limitations}

There were several limitations in the current study. First, the relatively small sample provided a narrow age range, which did not allow for examination of differences with age or gender. Second, the camp drew staff from a limited geographic region (mostly New England), as well as mostly college students (70\%). A more diverse sample that includes more variety in geographic location, age, and educational background may enhance the generalizability. A study with matched qualitative responses, instead of aggregated responses, may further explain individual barriers from the beginning to end of employment associated with creativity. The nonresponses on the open-ended question could be mitigated with a larger sample size or added participation incentive. Additionally, understanding specific support for traditions in camp would help further explain barriers to creativity. For example, periodic interviews throughout the camp season may help to probe into the more nuanced discussion surrounding barriers to creativity.

The results of this multi-method study suggested that first-year and returning camp counselors expectations and support for creativity varied at the beginning and end of employment. Camp counselors identified differences in organizational and coworker expectations for creativity as well as general work barriers to creativity. These findings suggest that camp counselors view creativity in their work context from both a subjective and holistic view, which related to their prior experience and general camp organization. Creativity continues to be a vital skill in the $21^{\text {st }}$ century, and therefore it is important to understand how creativity is perceived among counselors of various experience levels. To better support creativity and new ideas, counselors should be involved in training, programming, and overall culture of camp. The need for 


\section{Camp Support for Counselor Creativity}

creativity and critical thinking will be essential for the continued success of camp counselors. Previous research suggests supporting creativity helps with job satisfaction, production of new ideas, intrinsic motivation, and having a voice within an organization, but to date, no known studies had specifically assessed this phenomenon among camp counselors. This study adds to previous organizational behavior and summer camp literature, and highlights the importance of considering expectations for creativity when planning, developing, supporting, and managing counselors.

\section{Conclusion}

Creativity continues to be a vital skill in the $21^{\text {st }}$ century, and the need for creativity and critical thinking will be essential for the continued success of camp counselors. Previous research suggests work environments that support creativity and having a voice within an organization, help with job satisfaction, production of new ideas, and intrinsic motivation. However, to date, no known studies had specifically assessed this phenomenon among camp counselors.

Therefore, it is important to understand how creativity is perceived among counselors of various experience levels. The results of this multi-method study suggested that first-year and returning camp counselors' expectations and support for creativity varied at the beginning and end of employment. Camp counselors identified differences in organizational and coworker expectations for creativity as well as general work barriers to creativity. These findings suggest that camp counselors view creativity in their work context from both a subjective and holistic standpoint, which related to their prior experience and general camp organization. Therefore, to better support creativity and new ideas, counselors should be involved in training, programming, and overall culture of camp. This study adds to previous organizational behavior and summer camp literature, and highlights the importance of considering expectations for creativity when planning, developing, supporting, and managing counselors.

\section{References}

American Camp Association (2015). Business and operations report. Retrieved from: https://www.acacamps.org/press-room/aca-facts-trends

Amabile, T. M. (1997). Motivating creativity in organizations: On doing what you love and loving what you do. California Management Review, 40(1), 39-58. https://doi.org/10.2307/41165921

Amabile, T. M., Barsade, S. G., Mueller, J. S., \& Staw, B. M. (2005). Affect and creativity at work. Administrative Science Quarterly, 50(3), 367-403. 
Journal of Youth Development | http://jyd.pitt.edu/ | Vol. 15 Issue 1 DOI 10.5195/jyd.2020.795

\section{Camp Support for Counselor Creativity}

Amabile, T. M., Conti, R., Coon, H., Lazenby, J., \& Herron, M. (1996). Assessing the work environment for creativity. Academy of Management Journal, 39(5), 1154-1184.

\section{https://doi.org/10.5465/256995}

Archer, M. S. (2010). Routine, reflexivity, and realism. Sociological theory, 28(3), 272-303. https://doi.org/10.1111/j.1467-9558.2010.01375.x

Arnett, J. J. (2000). Emerging adulthood: A theory of development from the late teens through the twenties. American Psychologist, 55(5), 469-480.

Atchley, R. A., Strayer, D. L., \& Atchley, P. (2012). Creativity in the wild: Improving creative reasoning through immersion in natural settings. PloS One, $\pi(12)$, e51474. https://doi.org/10.1371/journal.pone.0051474

Bailey, A. W., Kang, H., \& Kuiper, K. (2012). Personal, environmental, and social predictors of camp staff burnout. Journal of Outdoor Recreation, Education, and Leadership, 4(3), 157-171. https://doi.org/10.7768/1948-5123.1134

Bandura, A. (1997). Self-efficacy: The exercise of control. New York, NY: W. H. Freeman.

Bolman, L. G., \& Deal, T. E. (1991). Reframing organizations. San Francisco, CA: Jossey-Bass.

Callero, P. L. (1985). Role-identity salience. Social Psychology Quarterly, 48(3), 203-215. http://dx.doi.org/10.2307/3033681

Callero, P. L., Howard, J. A., \& Piliavin, J. A. (1987). Helping behavior as role behavior: Disclosing social structure and history in the analysis of prosocial action. Social Psychology Quarterly, 50(3), 247256. https://doi.org/10.2307/2786825

Corbin, J., \& Strauss, A. (2015). Basics of qualitative research: Techniques and procedures for developing grounded theory. Thousand Oaks, CA: SAGE.

Deci, E. L., \& Ryan, R. M. (2012). Motivation, personality, and development within embedded social contexts: An overview of self-determination theory. In R. M. Ryan (Ed.), Oxford handbook of human motivation (pp. 85-107). Oxford, UK: Oxford University Press. https://doi.org/10.1093/oxfordhb/9780195399820.001.0001

DeGraaf, D., \& Glover, J. (2003). Long-term impacts of working at an organized camp for seasonal staff. Journal of Park \& Recreation Administration, 21(1), 1-20.

\section{https://js.sagamorepub.com/jpra/article/view/1514/1480}

Duerden, M. D., Witt, P., Garst, B., Bialeschki, D., Schwarzlose, T., \& Norton, K. (2014). The impact of camp employment on the workforce development of emerging adults. Journal of Park $\&$ Recreation Administration, 32(1), 26-44. https://js.sagamorepub.com/jpra/article/view/2989/4219

Eccles, J. S., \& Wigfield, A. (2002). Motivational beliefs, values, and goals. Annual Review of Psychology, 53(1), 109-132. https://doi.org/10.1146/annurev.psych.53.100901.135153 
Journal of Youth Development | http://jyd.pitt.edu/ | Vol. 15 Issue 1 DOI 10.5195/jyd.2020.795

\section{Camp Support for Counselor Creativity}

Eisenberger, R., \& Shanock, L. (2003). Rewards, intrinsic motivation, and creativity: A case study of conceptual and methodological isolation. Creativity Research Journal, 15(2-3), 121-130. https://doi.org/10.1080/10400419.2003.9651404

Ekvall, G. (1996). Organizational climate for creativity and innovation. European Journal of Work and Organizational Psychology, 5(1), 105-123. https://doi.org/10.1080/13594329608414845

Ellis, G. D., Jiang, J., Lacanienta, A., \& Carroll, M. (2019). Theming, co-creation, and quality of structured experiences at camp. Journal of Youth Development, 14(1), 230-242. https://doi.org/10.5195/jyd.2019.651

Farmer, S. M., Tierney, P., \& Kung-Mcintyre, K. (2003). Employee creativity in Taiwan: An application of role identity theory. Academy of Management Journal, 46(5), 618-630. https://www.jstor.org/stable/30040653

Gagné, M., \& Deci, E. L. (2005). Self-determination theory and work motivation. Journal of Organizational Behavior, 26(4), 331-362. https://doi.org/10.1002/job.322

Garst, B. A., \& Gagnon, R. J. (2016). A structural model of camp director practices and outcomes: Does intention toward program outcomes matter? Journal of Park \& Recreation Administration, 34(4), 51-65. https://doi.org/10.18666/JPRA-2016-V34-I4-7293

Glăveanu, V. P. (2015). Creativity as a sociocultural act. The Journal of Creative Behavior, 49(3), 165180. https://doi.org/10.1002/jocb.94

Goor, A., \& Rapoport, T. (1977). Enhancing creativity in an informal educational framework. Journal of Educational Psychology, 69(5), 636-643. https://doi.org/10.1037/0022-0663.69.5.636

Grube, J. A., \& Piliavin, J. A. (2000). Role identity, organizational experiences, and volunteer performance. Personality and Social Psychology Bulletin, 26(9), 1108-1119. https://doi.org/10.1177/01461672002611007

Henderson, K. A. (2007). Components of camp experiences for positive youth development. Journal of Youth Development, 1(3), 15-26. https://doi.org/10.5195/jyd.2007.371

Hendry, L. B., \& Kloep, M. (2007). Conceptualizing emerging adulthood: Inspecting the emperor's new clothes? Child Development Perspectives, 1(2), 74-79. https://doi.org/10.1111/j.17508606.2007.00017.x

Hill, E., \& Sibthorp, J. (2006). Autonomy support at diabetes camp: a self-determination theory approach to therapeutic recreation. Therapeutic Recreation Journal, 40(2), 107-125. https://js.sagamorepub.com/trj/article/view/961/936

Hosseini, A. S., \& Watt, A. P. (2010). The effect of a teacher professional development in facilitating students' creativity. Educational Research and Reviews, 5(8), 432-438. https://academicjournals.org/journal/ERR/article-full-text-pdf/2D1E4984177 
Journal of Youth Development | http://jyd.pitt.edu/ | Vol. 15 Issue 1 DOI 10.5195/jyd.2020.795

\section{Camp Support for Counselor Creativity}

Huang, L., Krasikova, D. V., \& Liu, D. (2016). I can do it, so can you: The role of leader creative selfefficacy in facilitating follower creativity. Organizational Behavior and Human Decision Processes, 132, 49-62. https://doi.org/10.1016/j.obhdp.2015.12.002

Kasser, T., Davey, J., \& Ryan, R. M. (1992). Motivation and employee-supervisor discrepancies in a psychiatric vocational rehabilitation setting. Rehabilitation Psychology, 37(3), 175-188. https://doi.org/10.1037/0090-5550.37.3.175

Kim, K. H. (2011). The creativity crisis: The decrease in creative thinking scores on the Torrance tests of creative thinking. Creativity Research Journal, 23, 285-295.

https://doi.org/10.1080/10400419.2011.627805.

Kirton, M. (1976). Adaptors and innovators: A description and measure. Journal of Applied Psychology, 61(5), 622-629. https://doi.org/10.1037/0021-9010.61.5.622

Ko, S., \& Butler, J. E. (2007). Creativity: A key link to entrepreneurial behavior. Business Horizons, 50(5), 365-372. https://doi.org/10.1016/j.bushor.2007.03.002

Louv, R. (2008). Last child in the woods: Saving our children from nature-deficit disorder. Chapel Hill, NC: Algonquin Books.

Lacanienta, A., Ellis, G., Taggart, A., Wilder, J., \& Carroll, M. (2018). Does theming camp experiences lead to greater quality, satisfaction, and promotion? Journal of Youth Development, 13(1-2). https://doi.org/10.5195/jyd.2018.535

Lynch, M. L., Hegarty, C. B., Trauntvein, N., \& Plucker, J. (2018). Summer camp as a force for $21^{\text {st }}$ century learning: Exploring divergent thinking and activity selection in a residential camp setting. Journal of Youth Development, 13(1-2), 286-305. https://doi.org/10.5195/jyd.2018.544

McCole, D., Jacobs, J., Lindley, B., \& McAvoy, L. (2012). The relationship between seasonal employee retention and sense of community: The case of summer camp employment. Journal of Park and Recreation Administration, 30(2). 85-101.

https://js.sagamorepub.com/jpra/article/view/2654/2559

McCrae, R. R. (1987). Creativity, divergent thinking, and openness to experience. Journal of Personality and Social Psychology, 52(6), 1258-1265. https://doi.org/10.1037/0022-3514.52.6.1258

Montuori, A., \& Purser, R. E. (1995). Deconstructing the lone genius myth: Toward a contextual view of creativity. Journal of Humanistic Psychology, 35(3), 69-112.

https://doi.org/10.1177/00221678950353005

Nowell, L. S., Norris, J. M., White, D. E., \& Moules, N. J. (2017). Thematic analysis: Striving to meet the trustworthiness criteria. International Journal of Qualitative Methods, 16(1), https://doi.org/10.1177/1609406917733847.

Oldham, G. R., \& Cummings, A. (1996). Employee creativity: Personal and contextual factors at work. Academy of Management Journal, 39(3), 607-634. 
Journal of Youth Development | http://jyd.pitt.edu/ | Vol. 15 Issue 1 DOI 10.5195/jyd.2020.795

\section{Camp Support for Counselor Creativity}

Plucker, J. A., Beghetto, R. A., \& Dow, G. T. (2004). Why isn't creativity more important to educational psychologists? Potentials, pitfalls, and future directions in creativity research. Educational Psychologist, 39(2), 83-96. https://doi.org/10.1207/s15326985ep3902 1

Plucker, J. A., Kaufman, J. C., \& Beghetto, R. A. (2015). What we know about creativity. Washington, DC: Partnership for $21^{\text {st }}$ Century Skills. Retrieved from: http://www.p21.org/our-work/4cs-researchseries/creativity

Ramsing, R., \& Sibthorp, J. (2008). The role of autonomy support in summer camp programs: preparing youth for productive behaviors. Journal of Park \& Recreation Administration, 26(2), 61-77. https://js.sagamorepub.com/jpra/article/view/1322/1290

Runco, M. A. (2015). Meta-creativity: Being creative about creativity. Creativity Research Journal, 273), 295-298. https://doi.org/10.1080/10400419.2015.1065134

Russ, S. W. (2014). Pretend play in childhood: Foundation of adult creativity. Washington, DC: American Psychological Association.

Russ, S. W., Robins, A. L., \& Christiano, B. A. (1999). Pretend play: Longitudinal prediction of creativity and affect in fantasy in children. Creativity Research Journal, 12(2), 129-139. https://doi.org/10.1207/s15326934crj1202_ 5

Ryan, R. M., \& Deci, E. L. (2000). Self-determination theory and the facilitation of intrinsic motivation, social development, and well-being. American Psychologist, 55(1), 68-78.

https://doi.org/10.1037110003-066X.55.1.68

Ryan, R. M., \& Deci, E. L. (2002). An overview of Self-determination Theory: An organismic-dialectical perspective. In E. L. Deci \& R. M. Ryan (Eds.), Handbook of self-determination research (pp. 333). Rochester, NY: The University of Rochester Press.

Shalley, C. E., Zhou, J., \& Oldham, G. R. (2004). The effects of personal and contextual characteristics on creativity: Where should we go from here? Journal of Management, 30(6), 933-958. https://doi.org/10.1016/j.jm.2004.06.007

Sheldon, K. M., Williams, G. C., \& Joiner, T. (2003). Self-determination theory in the clinic: Motivating physical and mental health. New Haven, CT: Yale University Press.

Shin, Y., Kim, M., \& Lee, S. H. (2017). Reflection toward creativity: Team reflexivity as a linking mechanism between team goal orientation and team creative performance. Journal of Business and Psychology, 32(6), 655-671. https://doi.org/10.1007/s10869-016-9462-9

Smith, C. A., Organ, D. W., \& Near, J. P. (1983). Organizational citizenship behavior: Its nature and antecedents. Journal of Applied Psychology, 68(4), 653-663. https://doi.org/10.1037/0021$\underline{9010.68 .4 .653}$

Soros, G. (2013). Fallibility, reflexivity, and the human uncertainty principle. Journal of Economic Methodology, 20(4), 309-329. https://doi.org/10.1080/1350178X.2013.859415 
Journal of Youth Development | http://jyd.pitt.edu/ | Vol. 15 Issue 1 DOI 10.5195/jyd.2020.795

\section{Camp Support for Counselor Creativity}

Tierney, P., \& Farmer, S. M. (2002). Creative self-efficacy: Its potential antecedents and relationship to creative performance. Academy of Management Journal, 45(6), 1137-1148. https://doi.org/10.2307/3069429

Tierney, P., \& Farmer, S. M. (2011). Creative self-efficacy development and creative performance over time. Journal of Applied Psychology, 96(2), 277-293. https://doi.org/10.1037/a0020952

Van den Broeck, A., Vansteenkiste, M., Witte, H., Soenens, B., \& Lens, W. (2010). Capturing autonomy, competence, and relatedness at work: Construction and initial validation of the work-related basic need satisfaction scale. Journal of Occupational and Organizational Psychology, 83(4), 981-1002. https://doi.org/10.1348/096317909X481382

Wahl-Alexander, Z., Richards, K. A., \& Washburn, N. (2017). Changes in perceived burnout among camp staff across the summer camp season. Journal of Park and Recreation Administration, 35(2), 7485. https://doi.org/10.18666/JPRA-2017-V35-I2-7417

Whittington, A., \& Garst, B. (2018). The role of camp in shaping college readiness and building a pathway to the future for camp alumni. Journal of Youth Development, 13(1-2), 105-125.

https://doi.org/10.5195/jyd.2018.519

Wilson, C., \& Sibthorp, J. (2018). Examining the role of summer camps in developing academic and workplace readiness. Journal of Youth Development, 13(1-2), 83-104. https://doi.org/10.5195/jyd.2018.563

Woodman, R. W., Sawyer, J. E., \& Griffin, R. W. (1993). Toward a theory of organizational creativity. Academy of Management Review, 18(2), 293-321. https://doi.org/10.2307/258761

Yoon, H. J., Sung, S. Y., Choi, J. N., Lee, K., \& Kim, S. (2015). Tangible and intangible rewards and employee creativity: The mediating role of situational extrinsic motivation. Creativity Research Journal, 274), 383-393. https://doi.org/10.1080/10400419.2015.1088283

Zhang, X., \& Bartol, K. M. (2010). Linking empowering leadership and employee creativity: The influence of psychological empowerment, intrinsic motivation, and creative process engagement. Academy of Management Journal, 53(1), 107-128. https://doi.org/10.5465/amj.2010.48037118

Zhou, J., \& George, J. M. (2001). When job dissatisfaction leads to creativity: Encouraging the expression of voice. Academy of Management Journal, 44(4), 682-696. https://doi.org/10.5465/3069410 